\title{
ALTERNATIVAS DEMOCRÁTICAS PARA O PROBLEMA DA BAIXA CONFIANÇA NA AÇÃO GOVERNAMENTAL
}

\author{
Carlos Bolonha ${ }^{1}$ \\ Maíra Almeida ${ }^{2}$ \\ Daniel Mitidieri Fernandes de Oliveira ${ }^{3}$
}

\begin{abstract}
Resumo
O presente artigo aborda a baixa confiança da população brasileira na ação governamental como um problema de direito constitucional. Inicialmente, o significado de ação governamental, bem como o seu conteúdo, é demarcado de acordo com uma revisão de literatura. Posteriormente, são analisados alguns acontecimentos recentes e alguns indicadores estatísticos que confirmam a baixa expectativa da população nas instituições públicas. Esse cenário de desconfiança é retratado como um efeito sistêmico negativo na atuação dos órgãos governamentais. Por fim, serão trabalhadas algumas alternativas visando a reduzir o quadro de desconfiança. $\mathrm{O}$ marco teórico do estudo é o institucionalista, na medida em que ele permite debater a legitimidade da ordem constitucional a partir dos efeitos produzidos pela atividade institucional.
\end{abstract}

Palavras-Chave: ação governamental; instituições; desconfiança; democracia; participação.

\section{INTRODUÇÃO}

O objetivo do estudo que se inicia é abordar a baixa confiança da população nas instituições governamentais como um problema de direito constitucional. O constitucionalismo contemporâneo investiga não apenas a efetivação dos direitos fundamentais ou a dificuldade contramajoritária no exercício da chamada jurisdição constitucional, mas também dedica atenção à legitimidade da ordem jurídica a partir do desempenho concreto de suas múltiplas instituições. Daí a proximidade entre confiança e Estado constitucional.

A existência de uma baixa confiança na ação governamental pode ser confirmada mediante a utilização

\footnotetext{
${ }^{1}$ Professor Adjunto da Graduação e da Pós-Graduação da Faculdade de Direito da Universidade Federal do Rio de Janeiro. Professor Orientador no Mestrado e Doutorado em Teoria do Estado e Direito Constitucional pela Pontifícia Universidade Católica do Rio de Janeiro. Pesquisador do Laboratório de Estudos Teóricos e Analíticos sobre o Comportamento das Instituições - LETACI/PPGD/FND/UFRJ, com o apoio da CAPES, CNPq e FAPERJ. E-mail: bolonhacarlos@gmail.com

${ }^{2}$ Doutoranda em Teorias Jurídicas Contemporâneas do Programa de Pós-Graduação em Direito - Faculdade Nacional de Direito - UFRJ. Pesquisadora do Laboratório de Estudos Teóricos e Analíticos sobre o Comportamento das Instituições LETACI/PPGD/FND/UFRJ, com o apoio da CAPES, CNPq e FAPERJ. Bolsista CAPES. E-mail: almeida.maira.1@gmail.com ${ }^{3}$ Mestrando em Teorias Jurídicas Contemporâneas do Programa de Pós-Graduação em Direito - Faculdade Nacional de Direito UFRJ. Pesquisador do Laboratório de Estudos Teóricos e Analíticos sobre o Comportamento das Instituições LETACI/PPGD/FND/UFRJ, com o apoio da CAPES, CNPq e FAPERJ. E-mail: danielmitidieri@yahoo.com.br
} 
de pesquisas de opinião realizadas nos últimos anos, demonstrando uma grande insatisfação do brasileiro com a política, com os governos e com os partidos. Como já estudado por outros autores, a desconfiança populacional nas instituições, sobretudo políticas, tem várias causas possíveis e também é identificada em outros países (GRIFFIN, 2015). Todavia, a desconfiança deve ser combatida, especialmente pelos efeitos sistêmicos negativos que ela gera.

Dois efeitos negativos da desconfiança devem ser considerados em especial. O primeiro deles é que a desconfiança opera em círculo vicioso. Um cenário de baixa confiança tende a gerar mais desconfiança, distanciando a população das instâncias majoritárias. O segundo efeito é que essa baixa credibilidade diminui a coesão social, tornando as políticas públicas disfuncionais ${ }^{4}$. Ora, governança real requer participação popular, deliberação, razão pública, medidas sem as quais não se constrói a estrutura necessária para um bom funcionamento do Estado Democrático de Direito.

Como lidar com a realidade de desconfiança? Deve-se pensar alternativas para o futuro, sobretudo as de cariz democrático. Afinal, é preciso recuperar a confiança da população nas instituições, sendo um caminho possível para isso a promoção de iniciativas de atuação prática mais transparente. Assim, um meio de diminuir a desconfiança seria incrementar alguns mecanismos de maior participação popular nos espaços majoritários ${ }^{5}$, como, por exemplo, o aumento no uso dos instrumentos de democracia participativa ${ }^{6}$ (audiências públicas etc.).

Nesse contexto, a importância do direito constitucional para o aprimoramento da prática institucional decorre do fato de que a Constituição Federal é a lei que, em um documento só, organiza os poderes, define os direitos fundamentais e estabelece os fins do Estado com alguma pretensão de permanência, dada a sua rigidez (BARROSO, 2003), constituindo-se em um verdadeiro sistema articulado de complexas normas jurídicas. Além disso, as normas constitucionais possuem reconhecida supremacia - formal e material - sobre as demais normas jurídicas, sendo ainda o estatuto guia da ação política em um Estado de Direito?

\footnotetext{
${ }^{4}$ Segundo Griffin: "Low trust can thorughly destroy organizations, societies and entire nations". GRIFFIN, Stephen M. Broken trust: dysfunctional government and constitutional reform. University Press of Kansas, 2015. p. 15.

5 “( ... ) sem prejuízo de reconhecer-se o valor intrínseco da democracia, (...)seria possível demonstrar que a democracia é capaz de produzir melhores resultados que as alternativas ditatoriais.” BARCELLOS, Ana Paula Gonçalves Pereira de. Direito Constitucional a um Devido Procedimento na Elaboração Normativa: Direito a Justificativa. Rio de Janeiro, 2015. Tese para o concurso de professora titular - Faculdade de Direito - Universidade do Estado do Rio de Janeiro, Rio de Janeiro, 2015, p. 54.

6 "[...] um conjunto de experiências e mecanismos que tem como finalidade estimular a participação direta dos cidadãos na vida política através de canais de discussão e decisão. A democracia participativa preserva a realidade do Estado (e a Democracia Representativa). Todavia, ela busca superar a dicotomia entre representantes e representados recuperando o velho ideal da democracia grega: a participação ativa e efetiva dos cidadãos na vida pública." SELL, Carlos Eduardo. Introdução à Sociologia Política: política e sociedade na modernidade tardia. Petrópolis, RJ: Vozes, 2006, p. 93.

${ }^{7 "}$ The working elements of a constitutional order are several and independent. The first is the text of the Constitution, 'the supreme law of the land' and an ineluctable source of authoritative rules, standards, and principles. A second element is the political and policy objectives of government officials, elites, and the public. A third, and mostly overlooked, element is the capacity of government institutions to act effectively. I have argued that there is a reciprocal relationship among the elements of a constitutional order." GRIFFIN, Op. cit., p. 37.
} 
Metodologicamente, o presente artigo não investiga a relação entre a baixa confiança na ação governamental e a necessidade de recompor as instâncias majoritárias por um prisma meramente legalista. Ao contrário, o trabalho reconhece a Constituição enquanto um sistema vivo, capaz de, em seu conjunto, gerar resultados testáveis. Para os fins aqui propostos, uma dimensão normativo-interpretativa da Constituição será subsidiária, pois aprimorar o desempenho de um sistema disfuncional envolve abordagens práticas, e não apenas exegese de textos de lei. Assume-se, então, uma metodologia institucional de análise de confiança, recorrendo-se a indicadores estatísticos.

A propósito, a constatação prática acerca da baixa confiança das instituições governamentais brasileiras leva em conta dois indicadores de medição. O primeiro indicador é o Índice de Confiança Social (ICS) ${ }^{8}$, criado pelo IBOPE, que mede como a sociedade civil avalia instituições públicas e privadas. O outro é o Índice de Confiança na Justiça no Brasil (ICJBrasil) da Escola de Direito da Fundação Getúlio Vargas de São Paulo, que afere o desempenho do Judiciário, bem como o de outras instituições do país.

Sendo assim, o artigo inicia pela noção de ação governamental. Em seguida, passa-se à análise fática e também estatística de que o poder público no Brasil ostenta um descrédito em face do tecido social. Os efeitos sistêmicos negativos dessa falta de confiança e os problemas que ela acarreta são abordados na sequência. Por fim, são pensadas algumas alternativas para reduzir essa baixa confiança, especialmente para aperfeiçoar o comportamento das instituições públicas, concluindo-se pela existência de caminhos possíveis para minorar a crise retratada.

\section{A AÇÃO GOVERNAMENTAL A LUZ DE UMA ABORDAGEM INSTITUCIONAL}

A ação governamental é uma expressão polissêmica. Dentre os vários significados possíveis de ação governamental, o artigo vai trabalhar com a noção que engloba toda ação estatal oriunda de órgãos tipicamente não-jurisdicionais. Essa exclusão do Poder Judiciário tem razão de ser no fato de que os órgãos da Justiça não são eleitos, não produzem normas jurídicas no sentido estrito do termo e atuam somente quando provocados, o que normalmente é chamado de inércia da jurisdição.

A premissa de excluir o Poder Judiciário da expressão ação governamental tem amparo nas lições de Karl Loewenstein. Esse autor alemão reconhece que o governo compreende ações legislativas e ações administrativas (LOEWENSTEIN, 1986, p. 56). A legislação e a execução das leis não são funções separáveis, mas diferentes técnicas do political leadership. Partindo de uma concepção de liderança política, pode-se afirmar, na esteira da tese de Loewenstein, que a atividade de governo conforma a vontade popular por meio de atos legislativos e atos administrativos de execução. 
Demarcado então o alcance da expressão ação governamental, ela pode envolver na prática atividades desde a aprovação de uma lei, cujo conteúdo a doutrina do direito reconhece como genérico e abstrato, como também medidas de diversas naturezas concretas: declarações, convocações, articulações, emissão de atos normativos secundários, alocação de recursos, formalização de decisões. Em suma, o exercício de direção da máquina pública exige um incessante processo de deliberação e escolha (GARCIA, 2001, p. 8) entre instituições.

Examinando o fenômeno governamental nessa perspectiva institucionalista, isto é, como problema conexo a vários polos de competência com atribuições sobre um tema, Maria Paula Dallari Bucci (2013, p. 205): o divide em três planos: o macro, o meso e o microinstitucional. O governo propriamente dito corresponde ao plano macroinstitucional, ao passo que o plano mesoinstitucional corresponde aos arranjos institucionais dos quais o governo se vale para canalizar suas ações. Por sua vez, o plano microinstitucional é a menor unidade programada do governo, ocupando a base dessa estrutura organizacional.

Necessariamente, a processualidade encontra-se presente nos três planos de competência da ação governamental, na medida em que, entre a formulação do problema e a implementação da escolha decisória para enfrentá-lo, faz-se necessária a conjugação de diversificados atos coerentes e juridicamente regulados. Segundo Maria Paula Dallari Bucci (2013, p. 110), a processualidade é um instrumento de atuação concreta do gestor público, consubstanciando importantes referenciais para a compreensão das decisões coletivas tomadas no âmbito da administração brasileira.

Tais decisões coletivas envolvem o somatório de vontades, técnicas e experiências, a fim de converter o impulso político em ação concreta, sujeita à participação e ao contraditório social. Esse sentido é bem mais sofisticado do que previa Rousseau em seu Contrato Social (1999), pois incrementa a possibilidade de uma dinâmica de consenso fora das assembleias legislativas. De tal modo, a ação governamental depende de expressões jurídico-institucionais bem estruturadas. Sustenta-se aqui que o fenômeno da baixa confiança da população na capacidade de o governo bem utilizar esses mecanismos e, com isso, atender ao interesse público tem a ver, entre outros fatores, com um déficit de participação popular na processualidade institucional do Estado.

Ainda hoje, após quase trinta anos de promulgação da Constituição Federal de 1988, a participação popular nas instituições públicas e governamentais é bastante limitada. De tal modo, para a ação governamental proceder de forma mais aberta, é preciso fortalecer mecanismos de maior participação popular. Caso contrário, o distanciamento do governo das expectativas da população, especialmente em uma sociedade marcada pelo pluralismo, potencializa o risco de equívocos e majora o sentimento de deslocamento entre cidadãos e classe política.

${ }^{8}$ Disponível em: http://www.ibopeinteligencia.com/arquivos/antigos/ics_brasil.pdf. Acesso em: 31 de maio de 2016. vol.10, no. 03, Rio de Janeiro, 2017.pp. 1332-1348 


\section{A BAIXA CONFIANÇA DA POPULAÇÃO BRASILEIRA NAS INSTITUIÇÕES GOVERNAMENTAIS: FATOS E INDICADORES ESTATÍSTICOS}

O ano de 2013 e seus protestos de rua marcaram a história recente do Brasil. Tais atos políticos foram observados em pelo menos vinte capitais do país, dando conta de expor inúmeros descontentamentos da população em face de temas que vão desde o custo das passagens de transporte urbano aos gastos elevados com obras para a Copa do Mundo da FIFA, que viria a ser realizada no ano seguinte (2014)9. Como não poderia deixar de ser, também não ficou de fora daquela onda de manifestações o combate à corrupção ${ }^{10}$.

As primeiras manifestações do Rio de Janeiro, no início de junho de 2013, contavam com poucos participantes. Na gênese do movimento, a palavra de ordem que se propagou ao longo dos atos impulsionados pelo Fórum de Lutas contra o Aumento da Passagem foi “Vem pra rua”. Demandava-se, inicialmente, a revogação do aumento da tarifa dos transportes de ônibus de R \$2,75 para R \$2,95 (LACERDA; PERES, 2013, p. 54-55). No entanto, os manifestantes e seus apoiadores passaram a proclamar "Não são só os 20 centavos", enumerando outras causas em questão, como o fim da desigualdade social e o direito à cidade (LACERDA; PERES, 2013, p. 66). Assim, as manifestações que começaram tímidas ganharam volume e em 20 de junho daquele ano contaram com mais de um milhão de adesões ${ }^{11}$.

A respeito desses episódios que irromperam no tecido social brasileiro, o filósofo Paulo Arantes possui uma avaliação. Segundo ele, "só as pedras de Brasília e adjacências fingem não saber que a política meramente política há tempos não pode mais nada salvo multiplicar seu poder de dano.” (2014, p.440) Interpretando essa opinião, pode-se constatar que o desempenho das instituições responsáveis por atender aos interesses da população está sistemicamente deficitário.

Todos esses fatos, descontentamentos e ineficiências governamentais repercutem não só no noticiário. Alguns institutos de pesquisa, como o Datafolha, o IBOPE e a Fundação Getúlio Vargas, possuem trabalhos voltados para a medição do índice de confiabilidade do brasileiro nas instituições.

Em 2015, por exemplo, pesquisa Datafolha ${ }^{12}$ feita entre os dias 9 e 13 de junho, com 2.125 pessoas, em

\footnotetext{
9 Disponível em: http://www.ebc.com.br/cidadania/2013/06/mobilidade-urbana-e-gastos-da-copa-sao-alvos-de-protesto-embrasilia acesso em: 27 de maio de 2016.

10 Disponível em: http://www.ebc.com.br/cidadania/2014/06/protestos-completam-um-ano-e-violencia-policial-se-repete Acesso em: 27 de maio de 2016

11 "As avaliações provenientes das mais diversas fontes oscilam entre 10 e 15 milhões de manifestantes em mais de quinhentas cidades. Enquanto não dispusermos de uma razoável coleção de relatos de todas as procedências, sobretudo das mais improváveis, continuará soterrada a memória viva do maior protesto de massa da história brasileira, com esta peculiaridade igualmente divisora de águas, a de que ele foi rigorosamente autoconvocado, ao contrário de episódios altamente coreografados, como as Diretas Já ou os caras-pintadas". ARANTES, Paulo Eduardo. O Novo Tempo do Mundo: e Outros Estudos sobre a Era da Emergência. Ed. Boitempo, $1^{a}$ Edição, São Paulo: 2014, p.378.

${ }^{12}$ Diponível em: http://www.conjur.com.br/2015-jul-08/oab-segunda-entidade-confiavel-pais-congresso-penultima Acesso em: 20 de maio de 2016.
} 
135 municípios, apontou as Forças Armadas e o Conselho Federal da $\mathrm{OAB}$ como as instituições nas quais o cidadão mais deposita sua confiança; nas que o cidadão menos confia, apareceram o Congresso Nacional e os Partidos Políticos.

A seu turno, o ICS - Índice de Confiança Social do IBOPE ${ }^{13}$, estruturado mediante pesquisa quantitativa com aplicação de questionário e entrevistas face a face, apresentou um resultado em 2015 em que a desconfiança da população aparece muito acentuada nos governos federal e municipal, por exemplo. As prefeituras, que em tese são governos mais próximos da vida da população, registraram um índice de confiança tão baixo quanto o do governo federal brasileiro, envolvido em severa crise política.

Já o relatório ICJ ${ }^{14}$ Brasil, da Escola de Direito da Fundação Getúlio Vargas de São Paulo, realiza pesquisas periódicas por meio de sondagens de tendência. As sondagens de tendência são levantamentos estatísticos que geram informações utilizadas no monitoramento da situação corrente e na antecipação de eventos futuros. A população alvo da pesquisa é composta pelos habitantes, com 18 anos ou mais, de oito unidades federativas (UF) brasileiras: Amazonas, Pernambuco, Bahia, Minas Gerais, Rio de Janeiro, São Paulo, Rio Grande do Sul e Distrito Federal, que juntos constituem aproximadamente 55\% da população brasileira acima dos 18 anos.

Criado há sete anos, o ICJ Brasil tem por objetivo retratar sistematicamente a confiança da população no Poder Judiciário. Não obstante, o resultado do ICJ Brasil do segundo semestre de 2015 inclui também um elenco de outras instituições públicas. Assim, cerca de um terço dos brasileiros afirmou confiar no Poder Judiciário, número equivalente à confiança nas Emissoras de TV (32\%) e muito próximo à confiança na Polícia (35\%).

Tal percentual encontra-se bastante abaixo de outras instituições como a Igreja Católica (57\%) e as Forças Armadas (61\%). Os brasileiros também confiam mais na Imprensa Escrita, nas Redes Sociais, no Ministério Público e nas Grandes Empresas, do que no Judiciário. Ainda assim, muito atrás do Poder Judiciário está a confiança nas esferas representativas, de modo que apenas 12\% dos brasileiros confiam no Congresso Nacional, 1 \% no Governo Federal e 6\% apenas nos Partidos Políticos.

Embora o sentimento populacional em face das instituições governamentais seja bastante depreciado, pesquisas desenvolvidas pelo Instituto de Pesquisa Econômica Aplicada (IPEA) ${ }^{15}$ acabam sendo um contraponto a esses indicadores de pouca confiança. Por exemplo, de 2009 a 2014, o número de indivíduos extremamente pobres diminuiu de 13.597 .606 para $8.191 .008^{16}$. Em outra frente, de 2009 a 2014, a renda domiciliar per capita

\footnotetext{
${ }^{13}$ Disponível em: http://www.ibopeinteligencia.com/arquivos/antigos/ics_brasil.pdf. Acesso em: 31 de maio de 2016.

${ }^{14}$ Disponível em: http://bibliotecadigital.fgv.br/dspace/bitstream/handle/10438/16539/Relato\%CC\%81rio\% 20ICJBrasil\%20\%202\%C2\%BA\%20sem\%202015.pdf?sequence=1\&isAllowed=y Acesso em: 20 de maio de 2016.

${ }^{15}$ Diponível em: http:/ /www.ipeadata.gov.br/ Acesso em: 20 de abril de 2016.

${ }^{16}$ Série calculada a partir das respostas à Pesquisa Nacional por Amostra de Domicílios (PNAD/IBGE). Disponível em: http://www.ipeadata.gov.br/ Atualizado em: 07/01/2016
} 
média subiu de $\mathrm{R} \$ 885,83$ para $1.152,24^{17}$. Isto é, algum resultado positivo as instâncias governamentais são capazes de gerar.

Até é possível afirmar que, nos últimos cinco anos, a vida média da população brasileira apresentou algumas melhoras relevantes em decorrência de agendas formuladas pelas instituições envolvidas com políticas públicas de desenvolvimento social, conforme indica o IPEA. Identifica-se, assim, a existência de um incremento em matéria de questões sociais relevantes, denotando a capacidade de os organismos governamentais pensarem ações institucionais através de argumentos de "razão pública", máxime em assuntos de justiça distributiva (RAWLS, 2000). Nada obstante esse relativo progresso, que não deve ser subestimado, os altos índices de desconfiança dos governos e da política conservam-se em pesquisas de opinião. Ou seja, os dados de baixa confiança continuam presentes e uma maneira de tentar alterá-los é mudar a forma como a população se relaciona com as instâncias governamentais no dia a dia.

\section{A BAIXA CONFIANÇA NA AÇÃO GOVERNAMENTAL COMO UMA QUESTÃO INSTITUCIONAL}

O conjunto apresentado de informações sobre a baixa confiança da população na ação governamental aponta para um déficitno funcionamento institucional do sistema político-constitucional brasileiro ${ }^{18}$.

Para a teoria institucionalista ${ }^{19}$ do direito, esse déficit não necessariamente se encontra localizado no plano da eficácia das normas constitucionais abstratas, ou na carência de métodos de interpretação concretizadora. O déficit pode operar nos mecanismos de funcionamento interno dessas organizações públicas dotadas de poder decisório, que devem estar alijando do processo valores e interesses socialmente relevantes. Deve-se, pois, realçar o plano do desempenho das instituições, de suas capacidades, de seus agentes e dos efeitos sistêmicos que eles provocam e sofrem em dimensão reflexiva, para que se possa cogitar alternativas de superação de defeitos.

A questão da confiança, para Stephen Griffin (2015), é central para o desempenho das instituições constitucionais. Isso porque a Constituição não cuida apenas de prever direitos, mas se ocupa de estabelecer uma

\footnotetext{
${ }^{17}$ Série calculada a partir das respostas à Pesquisa Nacional por Amostra de Domicílios (Pnad/IBGE), com valores reais aos preços vigentes na realização da última edição da pesquisa, atualizados conforme o deflator para rendimentos da Pnad apresentado pelo Ipeadata. Disponível em: http://www.ipeadata.gov.br/ atualizado em: 07/01/2016.

${ }^{18}$ Sobre esse ponto, é pertinente trazer a posição de John Rawls sobre instituição. Entende o autor por instituição um sistema público de regras que define cargos e posições com seus direitos e deveres. Pode ser considerada de dois modos. O primeiro como objeto abstrato, definido através de uma forma possível de conduta expressa por um sistema de regras. O segundo como a realização dessas condutas por certas pessoas em uma época e lugar. Ao se afirmar que uma instituição, como o Parlamento, integra um sistema público de regras, espera-se que os indivíduos nela engajados saibam quais os limites de suas condutas. Instituição, assim, pressupõe dois planos interligados, que dialogam entre si. (RAWLS, 2002, p. 58-59)

${ }^{19}$ Para mais detalhes sobre a teoria institucionalista no direito brasileiro, ver (SOUZA, BOLONHA, 2013); em língua inglesa ver (SUNSTEIN, VERMEULE, 2002).
} 
ordem de confiança entre instituições, governos e população em reciprocidade de convivência. Por mais que a opinião pública nem sempre seja isenta de paixões, não se deve descartar a existência de importantes indicadores de comportamento institucional em pesquisas de medição da satisfação da população.

Nesse sentido, a ordem constitucional não se resume ao que se encontra estabelecido normativamente em seu texto ou em emendas aprovadas posteriormente. Muito ao contrário. É o fenômeno da atividade institucional que vai efetivar a promoção dos direitos básicos da sociedade. De tal modo, se o desempenho de inúmeras instituições responsáveis por efetivar direitos é mal avaliado pelos destinatários de suas ações, passa a existir um problema de ordem constitucional a ser objeto de reflexão.

Com efeito, a existência de mau desempenho institucional representa empecilho para um satisfatório desenvolvimento dos direitos fundamentais no plano fático-social. À medida que problemas dessa ordem não são devidamente combatidos, a dificuldade democrática cresce ao longo do tempo, afetando gerações e gerações em acúmulo. Tal acumulado de déficits representa um alto risco para a credibilidade da ordem jurídica ao longo do tempo, com suas promessas pouco ou nada realizadas no campo das ações estatais, esvaziando a potencialidade das conquistas sociais.

A confiança na articulação de boas ações por parte dos governos pode ser representada metaforicamente por uma cola, que mantém unidos os indivíduos para coordenarem suas atividades com algum nível de segurança. Por mais que as necessidades humanas sejam infinitas e a capacidade de realização das instituições seja altamente limitada, a frustração sistêmica no agir dos órgãos com autoridade sobre o interesse público redunda em um conjunto crescente de desconfiança, gerando reflexos negativos cada vez maiores na vida das pessoas.

Não obstante essa realidade de descrédito, a responsabilidade por combatê-la não deve recair exclusivamente sobre as pessoas que ocupam posição circunstancial de autoridade. É preciso encontrar caminhos de redesenho institucional, ampliando a participação cidadã com vistas a superar tal crise de confiança. De fato, nem são necessárias rupturas no modelo constitucional vigente, bastando apenas alguns ajustes pontuais de menor escala, a fim de aprimorar práticas cotidianas.

Por sua vez, não é qualquer ajuste que deve ser empreendido. Toda proposta de mudança institucional deve buscar uma plataforma de trabalho compatível com o sistema constitucional posto. Adrian Vermeule (2007, p. 4) sustenta que o constitucionalismo democrático possui quatro valores centrais. São eles a imparcialidade, a responsabilidade, a transparência e a deliberação. Portanto, é com base em tais valores que a reflexão sobre melhoras no estado de desconfiança deve trilhar seu caminho.

A imparcialidade significa que a ação governamental deve realizar o bem comum em vez de os agentes públicos trabalharem em causa própria. A responsabilidade, de forma sucinta, envolve a necessidade de prestação de contas em face da comunidade política a qual o agente público pertence. A transparência precisa existir em 
algum grau, até para poder existir responsabilidade. E a deliberação é uma ferramenta essencial para troca de opiniões em um contexto político democrático.

A desconfiança na ação governamental indica que a população não vislumbra nas instituições responsáveis por administrar o interesse público pelo menos três dos quatro valores democráticos apontados, notadamente a imparcialidade, a responsabilidade e a deliberação. Como a transparência é um valor relativo e sujeito a calibragens, pode existir governo disfuncional, sem credibilidade, mas com alguma dose de transparência, situação que acaba sendo ambivalente e menos determinante.

É preciso desenvolver mecanismos de aprimoramento institucional, a fim de recuperar os indicadores de confiança da população, não descurando da imparcialidade, da responsabilidade e da deliberação. A desconfiança opera em círculo vicioso e fragmenta o tecido social, pondo em alerta a estabilidade dos valores da ordem jurídica vigente. Tendo em vista essa relação direta entre desconfiança e risco, é oportuno propor alternativas participativas, para aprimorar o funcionamento das instituições responsáveis por administrar o interesse público.

\section{ALTERNATIVAS DEMOCRÁTICAS PARA O PROBLEMA DA BAIXA CONFIANÇA NA AÇÃO GOVERNAMENTAL}

A doutrina contemporânea reconhece que o protagonismo político deve recair sobre as instâncias majoritárias (BARCELLOS, 2015). Portanto, este capítulo cuidará de incentivar três proposições visando fortalecer a ação governamental e, com isso, tentar reduzir o quadro de desconfiança que acomete as instituições públicas. Como se estudou anteriormente, a desconfiança afeta a legitimidade do sistema constitucional e compromete a obtenção de bons resultados no plano fático da ordem jurídica.

A primeira proposta para diminuir o problema da baixa confiança então é aumentar a participação popular nas instâncias de formulação administrativa. Embora, por exemplo, haja a previsão de realização de audiências públicas em inúmeras leis setoriais, o fato é que o expediente ainda é sujeito a critérios de conveniência e oportunidade por parte das autoridades competentes em levar a efeito programas e políticas públicas. E quando essa discricionariedade é utilizada em favor da consulta popular, não há uma processualidade definida para dar andamento aos trabalhos.

A institucionalização de uma processualidade mais participativa no âmbito da administração extroversa ${ }^{20}$ pode ser um caminho para se lograr uma maior legitimação na ação governamental. De fato, tal sugestão independe de reforma constitucional, podendo ser construída pelo legislador através de lei ordinária, inclusive

\footnotetext{
${ }^{20}$ A Administração Pública extroversa refere-se ao desempenho das atividades finalísticas administrativas que atingem diretamente os administrados/cidadãos, buscando a satisfação dos interesses coletivos. É a de caráter finalístico, tendo fulcro na Supremacia do Interesse Público e normas constitucionais destinadas aos entes políticos (é a relação Administração x Administrados/Cidadãos). Também pode ser chamada de Administração Pública Exógena.
} 
mediante o uso analógico do Código de Processo Civil (artigo 15) ${ }^{21}$.

A segunda proposição consiste em desburocratizar as técnicas de democracia direta, a partir de uma reforma da já antiga legislação de regência ${ }^{22}$. O plebiscito e o referendo são técnicas ainda pouco usuais, mas que representam um caminho para trazer ao debate temas que a cidadania almeja opinar. Ora, delegar todas as questões da vida em uma sociedade complexa a simples representantes eleitos quase sempre reduz as potencialidades do regime democrático.

A última proposta consiste no aperfeiçoamento do processo de elaboração das leis por parte dos órgãos legislativos, notadamente no que se refere à apresentação de razões justificadoras. Este encaminhamento tem o potencial de incrementar um sentimento de legitimação do processo político majoritário, não existente no contexto atual. Atualmente, o processo legislativo é mais organizado em jogo de lideranças e acordos de conveniência política do que propriamente via debates setoriais.

\section{Maior processualidade administrativa}

O que se pretendeu até agora foi apontar a baixa credibilidade que a cidadania deposita na ação governamental a partir de pesquisas de opinião. Para construir alternativas de mudança no atual quadro diagnosticado, é importante esboçar mecanismos pragmáticos, que passem por fortalecer um processo políticoadministrativo mais dialógico com os sujeitos constitucionais, o que acaba potencializando as chances de melhores resultados em face dos destinatários da ação política.

Como mencionado no tópico 2, a ação governamental não se resume à produção normativa. A concretização do direito, especialmente pelos órgãos da Administração pública, carece de uma série de ações coordenadas, a fim de gerar resultados satisfatórios e, sobretudo, com controlados gastos de recursos públicos, tanto de índole financeira quanto de material humano, na medida em que tais bens precisam ser controlados para por em marcha os inúmeros deveres que a Constituição outorga aos variados agentes governamentais nos três níveis de governo.

Maria Paula Dallari Bucci esclarece que as decisões relativas à alocação de recursos, deliberação de projetos e demais iniciativas de gestão do interesse público, compondo o pano de fundo da atuação governamental, apresenta uma multiplicidade de atores e uma diversidade de interesses. Trata-se de um desafio funcional de coesão do aparelho do Estado. Segundo a autora, quanto menos institucionalizada uma democracia

\footnotetext{
${ }^{21}$ Art. 15. "Na ausência de normas que regulem processos eleitorais, trabalhistas ou administrativos, as disposições deste Código lhes serão aplicadas supletiva e subsidiariamente." BRASIL. Código de Porcesso Civil. Disponível em: http://www.planalto.gov.br/ccivil_03/_ato2015-2018/2015/lei/113105.htm Acesso em: 20 de junho de 2016.

22 BRASIL. Lei No 9.709, de 18 de novembro de 1998. Disponível em: http://www.planalto.gov.br/ccivil_03/leis/19709.htm Acesso em: 20 de junho de 2016.
} 
for, menos regrada será a convivência entre os interesses distintos (BUCCI, 2013, p. 138).

Assim, o amadurecimento da democracia depende de ritos e formas de participação popular no interior das instituições curadores do interesse público, sob o risco de produção de resultados completamente deslocados do que se espera de uma gestão de interesses coletivos e antagônicos. Não é à toa que Adrian Vermeule ocupa-se mais de debater mecanismos de segunda ordem, relativos a arranjos e valores que devem presidir o funcionamento interno das instituições, do que refletir sobre a diferença de eficiência entre a adoção do sistema presidencialista ou do parlamentarista (2007).

No atual contexto de baixa confiança governamental, concorda-se com a autora quando ela diz que a processualidade representa a ordenação jurídica das relações do Estado com a sociedade, orientada para a aplicação do contraditório, de modo que as decisões relevantes, as que são tomadas fora das lides processuais compostas por juízes, sejam mediadas por um processo que incorpore o diálogo social, formalizado para absorver a necessidade de contraditório e estruturado para minimizar os naturais efeitos da frustração daqueles cujos interesses não foram contemplados.

No mesmo sentido, Ana Paula de Barcellos aduz que a democracia serve para a realização da igualdade e da autonomia pública das pessoas, independentemente dos resultados concretos que as decisões tomadas no contexto de sistemas democráticos produzem (BARCELLOS, 2015, P. 54). Isso não significa que os resultados estejam abertos, até porque a Constituição, notadamente a brasileira, estabelece valores substantivos a serem ressalvados da vontade da maioria. Mas aqui os resultados não são o problema; antes, deve-se ampliar os canais procedimentais.

A proposta sugerida então passa por permitir que as decisões coletivas tomadas no âmbito da Administração extroversa não sejam uma mera soma de interesses internos, mas um resultado advindo da integração dialógica de indivíduos, pessoas jurídicas, associações de classe, sindicatos e demais interessados em construir uma ação prática verdadeiramente concretizadora de direitos. Para tanto, fortalecer os mecanismos de orçamento participativo, audiências públicas obrigatórias e fóruns permanentes de discussão cumprem, em alguma medida, o papel de buscar o engajamento social.

O fortalecimento de uma processualidade administrativa, a qual não tem a ver com o processo administrativo utilizado pelos órgãos internos da Administração para controlar suas rotinas, mas com uma forma de diálogo obrigatório com a cidadania, tem muito potencial de diminuir a distância entre órgãos governamentais e a população, criando uma agenda pública de trabalho. Além da transparência, isso permite a chance de um maior preparo por parte dos atores envolvidos como forma de cunhar melhores argumentos na arena de discussão.

Para criar essa rotina dialógica, pequenas reformas setoriais dão conta de abrir a processualidade no âmbito administrativo, sem comprometer as agendas eleitas pelo voto a partir de uma intromissão de grupos 
oposicionistas.

Aliás, com a realização de audiências, oitivas e decisões finais formalizadas e motivadas, reduz-se o risco de captura dos órgãos executivos, dado o ganho em transparência que tais conjuntos de atos administrativos proporcionam. Além disso, a simples aproximação do indivíduo com a agenda governamental já servirá para uma maior percepção sobre a impessoalidade, a responsabilidade e a transparência da coisa pública.

É preciso reconhecer que a abertura da ação governamental a vozes que não pertençam ao quadro da Administração pública enriquece os processos de tomada de decisão, canaliza os interesses em disputa e amortece as divergências.

Em suma, as técnicas de audiência pública, orçamento participativo e demais mecanismos que reforçam uma processualidade no trato de interesses sociais relevantes devem se tornar compulsórios em alguma medida, a fim de que o povo, além de escolher representantes, possa também opinar sobre os meios pensados pelo governo no decorrer dos mandatos. Embora essa abertura participativa não iniba desvios, se bem conjugada com outras iniciativas, pode contribuir para recompor em níveis mais aceitáveis a satisfação da população com órgãos formuladores de políticas públicas.

\section{Abertura das técnicas de democracia direta}

Se a abertura da processualidade administrativa pode contribuir com a aproximação da população em face da Administração pública, as técnicas de democracia direta podem aproximar a população das grandes pautas congressuais. Não se prega aqui o assembleísmo na gestão do interesse público. O que se propõe é a possibilidade de o plebiscito e o referendo terem maior utilidade na construção de políticas públicas nacionais, até para um futuro exercício mais comedido da jurisdição constitucional.

Sobre a democracia direta em nível mais amplo, Griffin (2015, p. 151) alerta para a necessidade de dois elementos serem observados. $\mathrm{O}$ primeiro deles consiste em habilitar os cidadãos comuns para o exercício dos freios e contrapesos fora da estrutura governamental padrão, estabelecida pela Constituição. O outro elemento a ser conjugado na busca por uma democracia com elementos mais diretos seria a possibilidade de o Presidente ou o Congresso Nacional buscarem eleições sobre questões específicas, as quais não podem ser encontradas consensualmente no jogo político em função dos impasses decorrentes do sistema partidário posto.

Além disso, projetos rejeitados no Congresso Nacional ou vetados pelo Presidente da República por razões de puro jogo partidário poderiam ser submetidos de algum modo à opinião pública, para que uma nova proposta seja incentivada e um novo debate possa demarcar o alcance popular da opinião dos opositores. $\mathrm{O}$ uso da internet poderia baratear o custo que normalmente se produz em uma consulta popular tradicional, podendo ser incorporada como medida também de economia de tempo. 
O terceiro braço do tripé da democracia participativa é a iniciativa popular. Hoje ela possui um requisito muito rigoroso na Constituição para ser utilizado. Nos municípios ${ }^{23}$, a exigência é de $5 \%$ do eleitorado, enquanto que em âmbito federal ${ }^{24}$ ela precisa ser subscrita por no mínimo $1 \%$ do eleitorado nacional, distribuído pelo menos por cinco estados, com não menos de três décimos por cento de eleitores de cada um deles.

Ou seja, flexibilizar as regras para o uso da iniciativa popular pode incentivar a sociedade civil, especialmente os movimentos sociais, os sindicatos, as entidades de classe e as universidades e demais organizações civis a canalizarem demandas e pesquisas em projetos de lei a serem construídos em conjunto com o Congresso nacional, tal como recentemente se observou com a lei da "ficha limpa".

Enfim, os impasses político-partidários acabam sendo perversos. Uma iniciativa popular menos burocratizada pode sugerir uma pauta congressual sem necessariamente causar prejuízo à autoridade parlamentar. De fato, não existe fórmula pronta, mas algumas saídas podem ser pensadas com o que já existe à disposição no direito constitucional vigente, devendo-se apenas ajustar a intensidade de certos institutos.

\section{Elaboração normativa justificada}

A última proposta que se formula para reduzir o déficit de confiança na ação governamental consiste na efetivação do direito a um devido processo na elaboração normativa - DEPEN, construído por Ana Paula de Barcellos em sua tese para o concurso de professora titular da Universidade do Estado do Rio de Janeiro.

A professora reconhece que o direito constitucional tem muitos papéis na proteção e promoção dos direitos fundamentais. Um deles, porém, deve ser o de ordenar a atividade dos poderes majoritários, especialmente a elaboração normativa. Com isso, busca-se incrementar a democracia para além das cerimônias eleitorais. Segundo sua tese, quem apresenta proposições normativas está obrigado a apresentar uma justificativa correspondente.

Com efeito, essa justificativa precisa conter razões e informações sobre três conteúdos básicos: o problema que a proposta de normatização pretende enfrentar; os resultados cogitados; e os custos antecipados da medida sugerida. O descumprimento desse procedimento desencadearia uma inconstitucionalidade formal na norma editada.

O escopo do chamado devido processo de elaboração normativa - DEPEN é o de ampliar as razões e as informações fornecidas ao debate público acerca das proposições normativas. A reflexão específica sobre temas relevantes potencializa a democracia e desperta na cidadania uma co-responsabilidade pelos destinos do país. A percepção da legitimidade da vida pública só se aprimora se houver adesão da população às idéias subjacentes a

23 BRASIL. Constituição da República Federativo do Brasil. Art. 29, XIII. Disponível em: http://www.planalto.gov.br/ccivil_03/constituicao/constituicaocompilado.htm Acesso em: 30 de abril de 2016. 
cada projeto proposto. Só há adesão com justificativas e estudos de viabilidade, circunstância que torna mais digna de confiança a atividade legiferante.

A questão da qualidade da elaboração normativa coincide com uma preocupação já apontada por Jeremy Waldron (2003, p. 155), no sentido de que a legislação enfrenta pontos em que importantes interesses individuais estão sendo equilibrados e, se não houver cuidado, há risco de que alguns sejam oprimidos ou tratados injustamente.

Se no âmbito da Administração pública o incremento de uma processualidade formal contribui para democratizar tomadas de decisão no âmbito do Poder Executivo, um devido processo na elaboração normativa contribui para incrementar o debate de idéias no ambiente Legislativo, o que promove uma abertura das instâncias majoritárias ao dever de responsabilidade perante a comunidade política, abrindo a produção normativa ao alcance da cidadania.

Além disso, a conveniência prática do DEPEN é oferecer um rito de transparência ao presidencialismo de coalizão vigente, no qual as proposições originárias do Poder Executivo são aprovadas mais rapidamente e com reduzido espaço para debate e conhecimento das matérias, conforme bem chama atenção Barcellos (2015, p. 63).

O devido procedimento na elaboração normativa, assim, torna-se um corolário do princípio republicano e democrático, construindo uma publicidade consentânea com a era da velocidade e da informação em tempo real. Leis aprovadas "a toque de caixa" e apenas por razões de fisiologismo político oprimem a minoria, enfraquecem a divergência e transparecem que o objetivo partidário é apenas ocupar espaços de poder e não construir um projeto de país.

Enfim, o objetivo do presente tópico não é esgotar as temáticas da processualidade administrativa, dos instrumentos de democracia direta nem tampouco o recente estudo sobre um devido procedimento na elaboração normativa. Ao contrário, a proposta consiste em indicar a existência de mecanismos viáveis para buscar retirar a ação governamental dos atuais baixos indicadores de confiança.

Como bem alerta Griffin (2015, p. 35), se baixa confiança no local de trabalho já produz um ambiente desagradável, em que todos pouco prosperam, com o governo não é diferente. Aliás, se os governos podem operar com sucesso em uma atmosfera de desconfiança, eles seriam as únicas instituições modernas a lograr tal façanha. Portanto, não existe fórmula mágica para melhorar o cenário, senão experimentar alternativas que tenham custos aceitáveis e promovam uma participação popular mais acentuada, evitando-se constrangimentos autoritários.

\section{CONCLUSÃO}

As instituições políticas brasileiras passam por uma crise aguda de confiança. Corrupção, multiplicidade

\footnotetext{
${ }^{24}$ Ibid., Art. 61, $\$ 2$.
} 
de partidos desconhecidos, sistema eleitoral capturado por mecanismos obscuros de financiamento de campanha. Tudo isso não poderia gerar outro resultado senão indicadores de baixíssima confiança na capacidade de os governos melhorarem a vida da população. Não obstante o cenário de crise colocar à prova a estrutura de nosso sistema constitucional, qualquer medida fora da democracia tenderia a trazer ainda mais perdas.

Além de inventariar alguns exemplos de baixa confiança, o texto pretendeu demonstrar que a baixa confiança na ação governamental é um problema de direito constitucional. O problema constitucional decorre do fato de que a ordem jurídica é estruturada mediante arranjos institucionais responsáveis por distribuir competências. Se as instituições operam causando baixa confiança, isso significa que bons resultados não estão sendo gerados no exercício dessas competências, de modo que baixos resultados geram novamente baixa confiança.

Com efeito, o problema de baixa confiança não é somente brasileiro, muito embora o Brasil não deva com isso se conformar. E uma forma de não conformação é sugerir frentes que combatam a formação de torres de marfim, as quais isolam do povo a participação nas decisões coletivas.

O fortalecimento democrático que se propõe passa pela reaproximação dos governos com a população em geral. Além de essa reaproximação ser viável no plano teórico sem elevados exercícios de divagação intelectual, há saídas já pensadas na própria legislação nacional. Basta apenas ampliar certos mecanismos em escalas ainda não testadas. As ferramentas existem, o caldo de cultura é apropriado e o momento pede menos inércia democrática, porque o estado de direito só se legitima com debate e participação amplificados.

Feitas essas considerações, a tentativa do estudo foi indicar a existência de uma realidade institucional insatisfatória. Mas a constatação dessa realidade não bastou. Procurou-se também apontar alguns caminhos possíveis para permitir uma ampliação de legitimidade desses órgãos atualmente em descrédito. Mesmo algumas mudanças legislativas serem imprescindíveis, o que pode redundar em uma exortação infrutífera, confia-se no importante papel que cumpre o pesquisador do direito quando reflete alternativas de aprimoramento do ambiente institucional brasileiro.

\section{DEMOCRATIC ALTERNATIVES FOR THE CONCERN OF THE LOW RELIANCE ON GOVERNMENT ACTION}

\section{Abstract}

This article discusses the low confidence of the population in government action as a constitutional law issue. Initially, the meaning of government action as well as its content, is marked according to a literature review. Subsequently, we analyze some recent events and some statistical indicators confirm the low expectations of the population in public institutions. This scenario of mistrust is portrayed as a negative systemic effect on the 
performance of government agencies. Finally, will be worked some alternatives in order to reduce the mistrust frame. The theoretical framework of the study is the institutionalist, in that it allows debate the legitimacy of the constitutional order from the effects produced by institutional activity.

Keywords: government action; institutions; distrust; democracy; participation.

\section{REFERÊNCIAS}

ARANTES, Paulo Eduardo. O Novo Tempo do Mundo: e Outros Estudos sobre a Era da Emergência. Ed. Boitempo, São Paulo: 2014.

BARCELlOS, Ana Paula Gonçalves Pereira de. Direito Constitucional a um Devido Procedimento na Elaboração Normativa: Direito a Justificativa. Rio de Janeiro, 2015. Tese para o concurso de professora titular Faculdade de Direito - Universidade do Estado do Rio de Janeiro, Rio de Janeiro, 2015.

BARROSSO, Luís Roberto. O Direito Constitucional e a Efetividade de Suas Normas. Ed. Renovar, 7 ed. Rio de Janeiro: 2003 .

BRASIL. Constituição da República Federativo do Brasil. Disponível em: http://www.planalto.gov.br/ccivil_03/constituicao/constituicaocompilado.htm Acesso em: 30 de abril de 2016.

BUCCI, Maria Paula Dallari. Fundamentos para uma Teoria Jurídica das Políticas Públicas. Ed. Saraiva. São Paulo: 2013.

GARCIA, Ronaldo Coutinho. Subsídios para organizar avaliações da ação governamental. Planejamento e Políticas Públicas v.1 - n.1 - jun. 1989. Brasília: Instituto de Pesquisa Econômica Aplicada, 2001.

GRIFFIN, Stephen M. Broken trust: dysfunctional government and constitutional reform. University Press of Kansas, Kansas: 2015.

LACERDA, Renata Barbosa; PERES, Thiago Brandão. "Jornadas de Junho: Explorando os Sentidos da Indignação Social Contemporânea no Brasil”. Revista Enfoque, vol. 13, Rio de Janeiro: 2013. Disponível em: http://www.enfoques.ifcs.ufrj.br/ojs/index.php/enfoques/article/viewFile/198/183 Acesso em 27 de abril de 2016.

LOEWENSTEIN, Karl. Teoria de La Constituición. Tradução para o espanhol por Alfredo Gallego Anabitarde. Barcelona: Ariel, 1986.

RAWLS, John. Uma Teoria da Justiça. - 2a ed. - São Paulo: Martins Fontes, 2002. Liberalismo Político. - São Paulo: Instituto Teotônio Vilela, 2000.

ROUSSEAU, Jean-Jacques. O Contrato Social - Princípios de Direito Político. 19 ed. - Rio de Janeiro: Ediouro, 1999.

SELL, Carlos Eduardo. Introdução à Sociologia Política: política e sociedade na modernidade tardia. Petrópolis, RJ: Vozes, 2006. 
SOUZA, Rafael Bezerra de; BOLONHA, Carlos. Teorias Jurídicas Contemporâneas: uma análise crítica sob a perspectiva institucional. Direito, Estado e Sociedade: nº 43. Jul/ Dez 2013.

SUNSTEIN, Cass; VERMEULE, Adrian. Interpretation and Institutions. Chicago Public Law and Legal Theory Working Paper Series, Chicago, n. 28, 2002.

VERMEULE, Adrian. Mechanisms of Democracy: Institutional Design Writ Smal. Oxford University Press. Oxford: 2007.

WALDRON, Jeremy. A Dignidade da Legislação. Martins Fontes. São Paulo: 2003.

Trabalho enviado em 02 de jultho de 2016.

Aceito em 05 de fevereiro de 2017. 